\title{
Power Tracking Control of Domestic Induction Heating System using Pulse Density Modulation Scheme with the Fuzzy Logic Controller
}

\author{
Booma Nagarajan ${ }^{\dagger}$, Rama Reddy Sathi* and Pradeep Vishnuram**
}

\begin{abstract}
Power requirement to the induction heating system varies during the heating process. A closed loop control is required to have a smooth control over the power. In this work, a constant frequency pulse density modulation based power tracking control scheme for domestic induction heating system is developed using the Fuzzy Logic Controller. In the conventional power modulation schemes, the switching losses increase with the change in the load. The proposed pulse density modulation scheme maintains minimum switching losses for the entire load range. This scheme is implemented for the class-D series resonant inverter system. Fuzzy logic controller based power tracking control scheme is developed for domestic induction heating power supply for various power settings. The open loop and closed loop simulation studies are done using the MATLAB/Simulink simulation tool. The control logic is implemented in hardware using the PIC16F877A microcontroller. Fuzzy controller tracks the set power by changing the pulse density of the gate pulses applied to the inverter. The results obtained are used to know the effectiveness of the fuzzy logic controller to achieve the set power.
\end{abstract}

Keywords: Closed loop control, Fuzzy logic controller, Induction heating, Pulse density modulation

\section{Introduction}

Induction heating $(\mathrm{IH})$ load requires high frequency power supply to induce high frequency eddy currents in the work-piece which result in heating effect. IH technique is used to produce high temperature for domestic cooking and many industrial applications like steel melting, brazing and surface hardening. For these applications, the operating frequency must be selected based on the work-piece geometry and skin depth requirements [1]. Advanced technology in development of the high frequency semiconductor switches has made it possible to introduce new switching devices with sophisticated functions in a smaller size at a lower price. Recent developments in power electronic devices and switching schemes have made the voltage source fed series resonant inverter (SRI) suitable for IH applications [2-4]. Different modulation schemes for the resonant inverters are developed to vary the output power. The output power can be controlled by varying the switching frequency using pulse frequency modulation (PFM) technique [5-8]. The phase shift (PS) control technique varies the output power by phase shifting the pulses applied to the power switches of the inverter [911]. The asymmetrical duty cycle (ADC) control technique

$\dagger$ Corresponding Author: Dept. of Electrical and Electronics Engineering, Jerusalem College of Engineering, Chennai, India. (boomannagarajan@yahoo.com)

* Dept. of Electrical and Electronics Engineering, Jerusalem College of Engineering, Chennai, India. (srr.victory@gmail.com)

** Dept. of Electrical and Electronics Engineering, Jerusalem College of Engineering, Chennai, India. (pradeep.kannan03@gmail.com)

Received: December 26, 2013; Accepted: June 6, 2014 employs an unequal duty operation of the switches in the inverter. Accuracy in the output power control is very important in IH applications. For example, domestic cooking appliances require accurate power control over a wide range of load with high efficiency. To improve the efficiency of SRI, zero voltage switching (ZVS) operating condition must be maintained over the entire load range. In the conventional fixed frequency modulation techniques, the ZVS condition is ensured only for limited range of duty cycle [12]. In the above mentioned methods, the output power control is difficult due to the variation of IH load parameters during the heating process [13-15]. With the variation in load parameters, non-ZVS operating condition results during the switching operation which causes more power losses $[16,17]$. The above literature does not deal with the power tracking control of domestic induction cooking system using pulse density modulation (PDM). The PDM technique regulates the output power by varying the period in which the inverter injects high frequency current to the induction coil. For the load range of $(0-$ 100) $\%$, the ZVS condition is maintained in the PDM based control scheme. This power control scheme satisfies the variable power requirement of the load with the minimum switching losses. Since the switching frequency is not varied, the switching loss is minimum and constant throughout the entire load range. This paper discusses the power control of class-D SRI using PDM technique in open loop and closed loop operation. In the closed loop operation, fuzzy logic controller (FLC) based power tracking of the various power settings is proposed. The PID controller based conventional scheme is replaced with the 


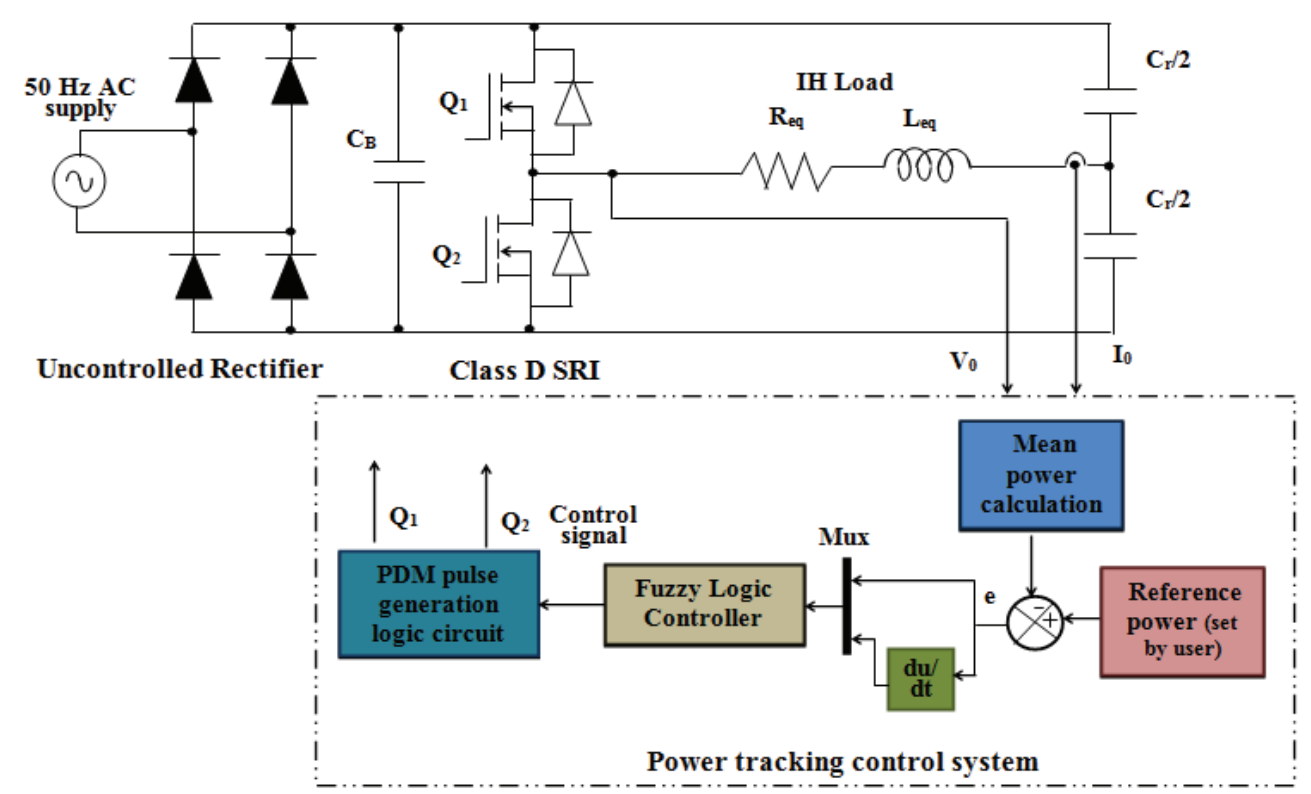

Fig. 1. Schematic diagram of the IH power supply system with the FLC based control scheme

FLC. The closed loop operation ensures the tracking of reference power set by the user in their induction cooking system.

\section{Description of the Power Converter}

The Fig. 1 shows the main circuit diagram of the class-D SRI fed IH load. Uncontrolled rectifier is used to convert the single phase $\mathrm{AC}$ input voltage $\left(\mathrm{V}_{\mathrm{i}}\right)$ of $50 \mathrm{~Hz}$ frequency into DC. In order to filter the ripple content, a DC link capacitor $\left(C_{B}\right)$ is used. Then the $D C$ input voltage $\left(V_{B}\right)$ is given to the inverter to produce high frequency $\mathrm{AC}$ which is essential for IH system. This high frequency AC current $\left(\mathrm{i}_{\mathrm{o}}\right)$ is applied to the IH coil, and the pan gets heated up. $\mathrm{R}_{\mathrm{eq}}$ and $\mathrm{L}_{\mathrm{eq}}$ are the equivalent resistance and inductance of the IH coil and the pan. The resonant operating condition is achieved using a resonant capacitor $\left(C_{r}\right)$ which is considered equally on both sides of the bridge. The switches $\mathrm{Q}_{1}$ and $\mathrm{Q}_{2}$ are the MOSFET switches with antiparallel diodes. These switches are alternatively turned on/off with the high frequency PDM pulses generated by the FLC based control scheme to produce the reference power set by the user.

\section{Principle of PDM Technique}

In PDM technique, the switching frequency of the inverter is kept constant and it is chosen slightly greater than the load resonant frequency in order to reduce the switching losses. The logic circuit for the generation of the PDM based pulses is shown in Fig. 2. High frequency $25 \mathrm{kHz}$ pulses are logically compared with the low

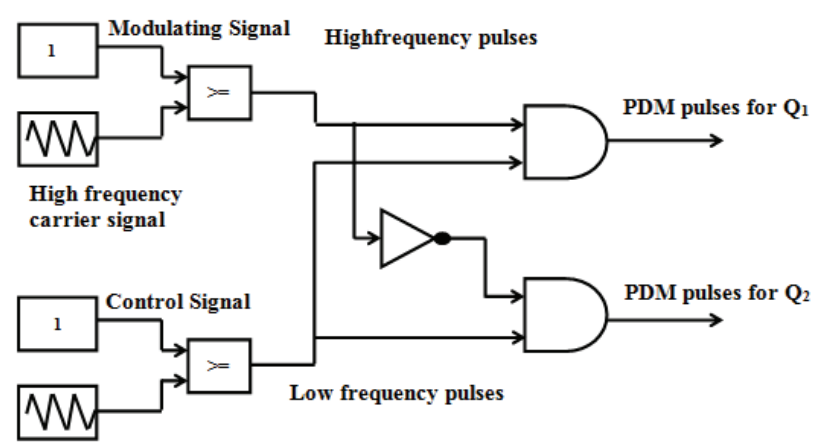

Low frequency carrier signal

Fig. 2. Gate pulse generation circuit for the switches of the inverter

frequency $20 \mathrm{~Hz}$ pulses. Pulses for the switches $\mathrm{Q}_{1}$ and $\mathrm{Q}_{2}$ are generated when the low frequency signal goes high as given in Fig. 3. When the low frequency pulse goes low, the switches $Q_{1}$ and $Q_{2}$ do not receive the gate pulses and they remain in, off condition.

Waveforms for the output voltage $\left(\mathrm{V}_{\mathrm{o}}\right)$ and the output current $\left(\mathrm{I}_{\mathrm{o}}\right)$ of SRI with PDM control are given in Fig. 4.

From the waveforms, it can be observed that the envelope of the current follows a first-order response even though the inverter system is a second order system. For the control of output power, it is important to analyze the output power of the inverter with PDM control. The envelope of the current $\left(i_{E}\right)$ is given by,

$$
\begin{gathered}
i_{E}(t)=I_{m}\left(1-e^{\frac{T_{O N}}{\tau}}\right)+I e^{-\frac{t}{\tau}}\left(0 \leq t \leq T_{O N}\right) \\
i_{E}(t)=i_{1}\left(T_{O N}\right) e^{-\frac{t-T_{O N}}{\tau}}\left(T_{O N} \leq t \leq T_{P D M}\right)
\end{gathered}
$$



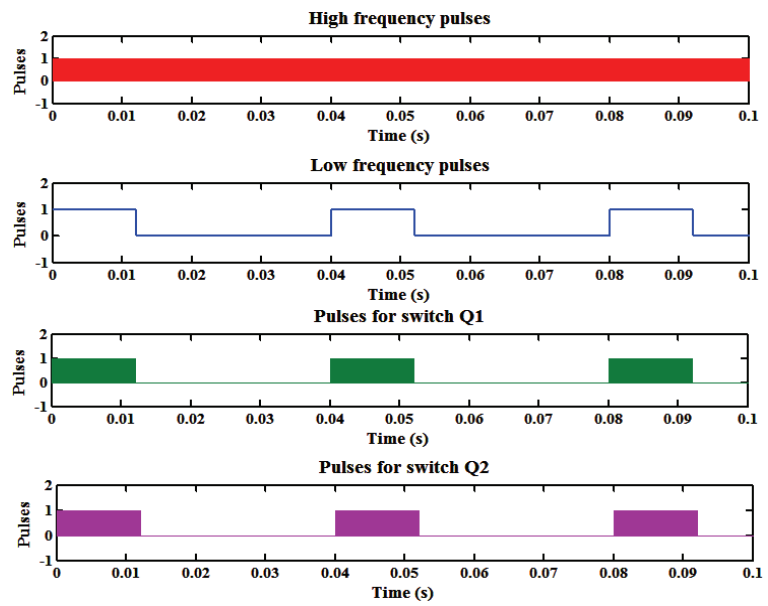

Fig. 3. Generation of the PDM pulses for the switches $Q_{1}$ and $\mathrm{Q}_{2}$

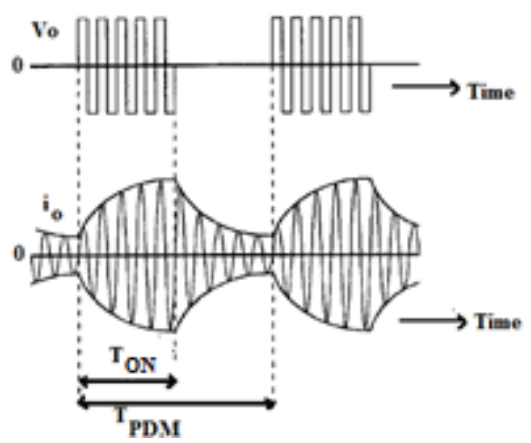

Fig. 4. Key waveforms of the SRI with the PDM control.

$$
I=I \frac{1-e^{-\frac{T_{O N}}{\tau}}}{1-e^{-\frac{T_{P D M}}{\tau}}}
$$

Where, $\mathrm{T}_{\mathrm{PDM}}$ is the total control period for PDM operation and $T_{O N}$ is the total on period of the switch. $I$ is the initial value of the envelope $i_{E}$ and $I_{m}$ is the maximum current at the rated power operation of the inverter. The amplitude of the $\mathrm{i}_{\mathrm{E}}$ is directly proportional to the pulse density.

$$
\lim _{\tau \rightarrow \infty} i_{E}=I_{m}\left(\frac{T_{O N}}{T_{P D M}}\right)
$$

In PDM based SRI, the average output power $(\mathrm{P})$ is obtained by multiplying $\mathrm{V}_{\mathrm{B}}$ and $\mathrm{i}_{\mathrm{E}}$ as follows,

$$
\begin{aligned}
P= & \frac{1}{T_{P D M}} \int_{0}^{T_{O N}} \frac{2}{\pi} V_{B} i_{E}(t) d t=\frac{2}{\pi} V_{B} I_{M}\left[\frac{T_{O N}+\tau_{e}^{-\frac{T_{O N}}{\tau}}-\tau}{T_{P D M}}\right] \\
& +\frac{2}{\pi} V_{B} I_{m}\left[\frac{\tau}{T_{P D M}} \frac{e^{\frac{T_{O N}}{\tau}}-1}{e^{\frac{T_{P D M}}{\tau}}-1}\right]
\end{aligned}
$$

$$
\left(1-e^{-\frac{T_{O N}}{\tau}}\right)
$$

With $\mathrm{T}_{\mathrm{PDM}}>>\tau$, the output power is in proportion to the pulse density as given below.

$$
\lim _{\tau \rightarrow \infty} P=\frac{2}{\pi} V_{B} I_{m}\left(\frac{T_{O N}}{T_{P D M}}\right)
$$

During every mask period of the pulses, the freewheeling of resonant current takes place in the load side such that the energy stored in the inductor and capacitor is dissipated in the load. The PDM duty cycle $\left(\mathrm{D}_{\mathrm{PDM}}\right)$ is given by,

$$
D_{P D M}=\frac{T_{O N}}{T_{P D M}}
$$

The $\mathrm{D}_{\text {PDM }}$ must be selected such that the low frequency signal must be less than $20 \mathrm{~Hz}$ to avoid acoustic noise. The average output power $\left(\mathrm{P}_{\mathrm{o}}\right)$ can be calculated in terms of $\mathrm{D}_{\mathrm{PDM}}$ using the following equation.

$$
P_{o}=D_{P D M} P_{\text {rated }}
$$

Where, $\mathrm{P}_{\text {rated }}$ is the output power with $\mathrm{D}_{\mathrm{PDM}}$ equal to one. The output power could be controlled by controlling the $\mathrm{D}_{\mathrm{PDM}}$. Since the switching frequency is constant, even with the variation in $\mathrm{D}_{\mathrm{PDM}}$, the turn on and turn off instants of the switches are not varied in PDM method. Hence the ZVS condition is maintained throughout the load cycle. This reduces the switching losses in the high frequency SRI.

\section{Simulation Results}

\subsection{Open loop study of IH system with PDM control}

The simulink model of the open loop system with class-D resonant inverter is shown in Fig. 5. The parameters used for the simulation are listed below: $\mathrm{f}_{\mathrm{s}}=25 \mathrm{kHz}, \mathrm{R}_{\mathrm{eq}}=5 \Omega$, $\mathrm{L}_{\text {eq }}=0.3 \mathrm{mH}, \mathrm{C}_{\mathrm{r}} / 2=0.65 \mu \mathrm{F}, \mathrm{P}_{\text {rated }}=100 \mathrm{~W}$. The PDM pulses for the switches $\mathrm{Q}_{1}$ and $\mathrm{Q}_{2}$ are generated as discussed earlier. By varying the $\mathrm{D}_{\mathrm{PDM}}$ of the low frequency signal, the output power can be controlled. The rated output power is obtained for the $\mathrm{D}_{\mathrm{PDM}}$ of $100 \%$. To prove the variation in power with the $\mathrm{D}_{\mathrm{PDM}}$ signal, the simulation is carried out for duty cycles of $70 \%$ and $30 \%$ respectively. For the rated power of $100 \mathrm{~W}$, the high switching frequency $\left(f_{s}\right)$ and the low frequency $\left(\mathrm{f}_{\mathrm{PDM}}\right)$ are chosen as $25 \mathrm{kHz}$ and $20 \mathrm{~Hz}$ respectively. Fig. 6(a) illustrates the output voltage waveform with $70 \%$ of $\mathrm{D}_{\mathrm{PDM}}$.

The output current and the real power for $70 \%$ of $\mathrm{D}_{\mathrm{PDM}}$ 


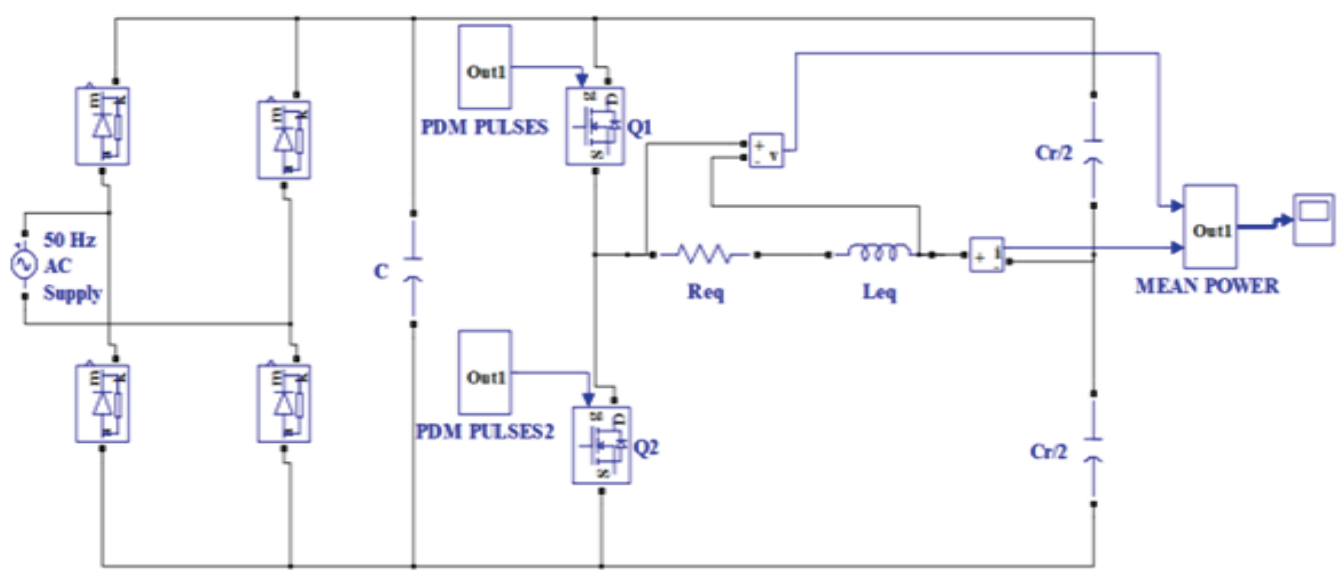

Fig. 5. Simulink model of the open loop system

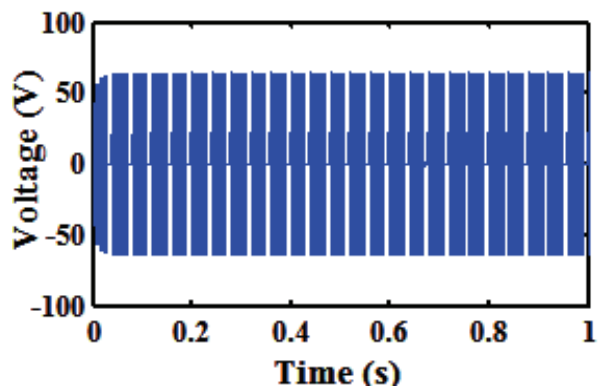

(a)

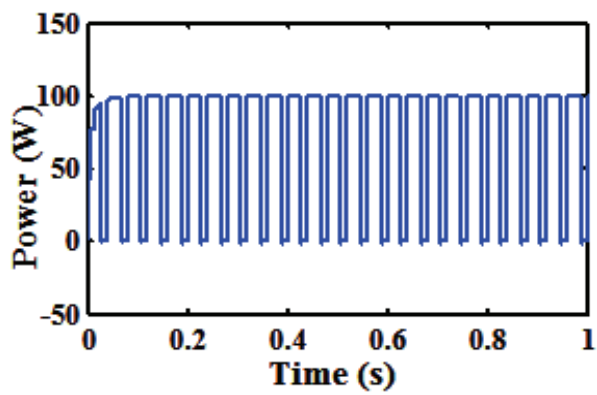

(c)

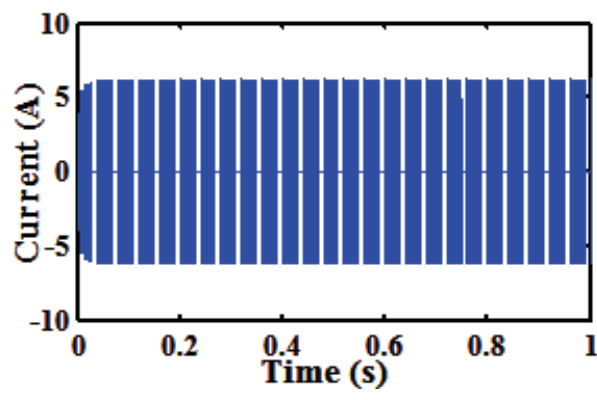

(b)

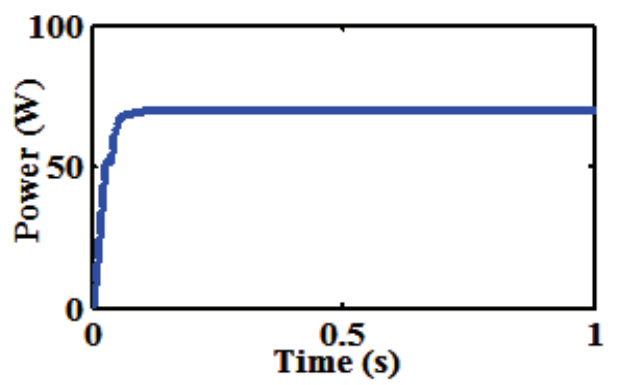

(d)

Fig. 6. Simulation Results (a) Output voltage waveform with $70 \%$ of $\mathrm{D}_{\text {PDM }}$ (b) Output current waveform with $70 \%$ of $\mathrm{D}_{\text {PDM }}$ (c) Output power waveform with $70 \%$ of $\mathrm{D}_{\mathrm{PDM}}(\mathrm{d})$ Average output power with $70 \%$ of $\mathrm{D}_{\mathrm{PDM}}$

are presented in Figs. 6(b) and Fig. 6(c) respectively. Since the voltage and current are in discontinuous form, the average value of the power is measured and it is shown in Fig. $6(\mathrm{~d})$. When the $\mathrm{D}_{\text {PDM }}$ is $70 \%$, the average current and the voltage get lowered due to the discontinuous flow of $\mathrm{V}_{\mathrm{o}}$ and $\mathrm{I}_{0}$. This causes the reduction of the average output power from $100 \mathrm{~W}$ to $70 \mathrm{~W}$. Similarly the switches are operated with $\mathrm{D}_{\mathrm{PDM}}$ of $30 \%$ and the corresponding waveforms of output voltage, output current, instantaneous power and average output power are shown in Figs. 7(a), $7(\mathrm{~b}), 7(\mathrm{c})$ and $7(\mathrm{~d})$ respectively. The average power is about $30 \mathrm{~W}$ with $30 \% \mathrm{D}_{\mathrm{PDM}}$. The output voltage is a high frequency waveform and hence the driving pulses to the switches, the zoomed view of the voltage and current are shown in Figs 7(e), 7(f) and 7(g) respectively. The average output power changes linearly with the change in the value of the $\mathrm{D}_{\mathrm{PDM}}$, in PDM technique. It has been found from the simulation results that, by controlling the $\mathrm{D}_{\mathrm{PDM}}$ from $0 \%$ to $100 \%$, the average value of the output power can be controlled.

\subsection{FLC based power control of IH load}

In domestic IH system, according to the heating requirement, the power setting is changed by the user. Different modulation schemes are available to perform power control for IH load. This section discusses the development of FLC for the power control of IH system using PDM technique. 


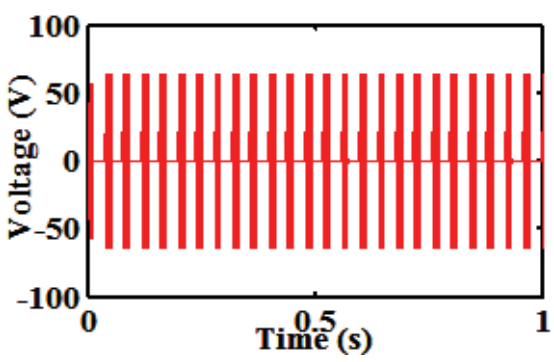

(a)

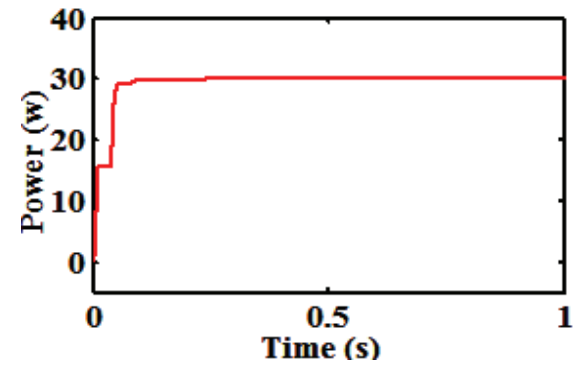

(d)

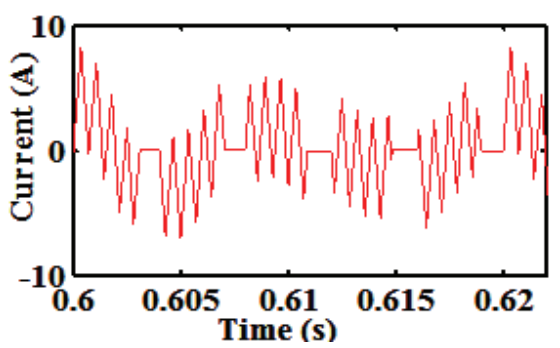

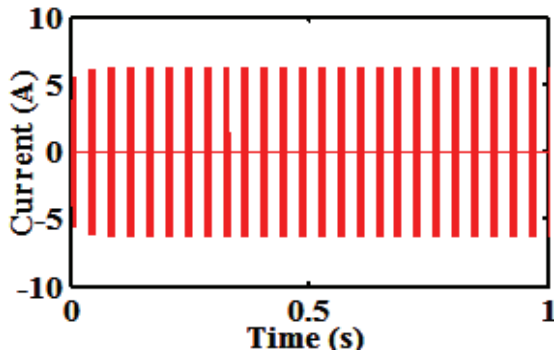

(b)

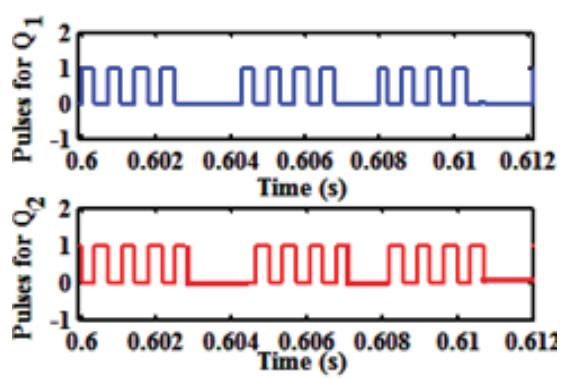

(e)

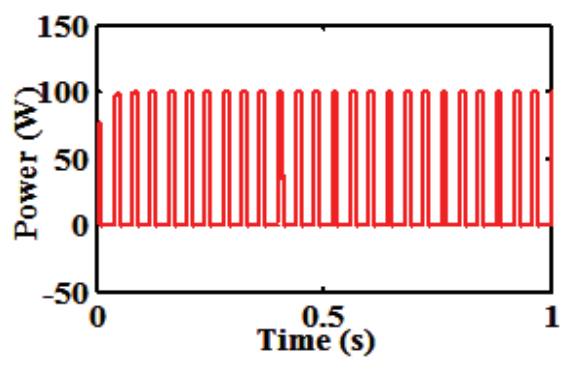

(c)

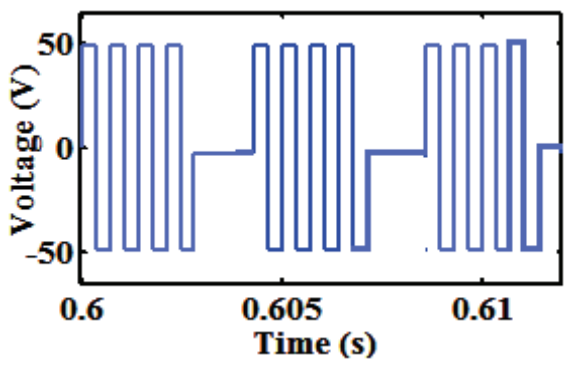

(f)

Fig. 7. Simulation Results(a) Output voltage waveform with $30 \%$ of $\mathrm{D}_{\mathrm{PDM}}$ (b) Output current waveform with $30 \%$ of $\mathrm{D}_{\mathrm{PDM}}$ (c) Output power waveform with $30 \%$ of $\mathrm{D}_{\mathrm{PDM}}(\mathrm{d})$ Average output power waveform with $30 \%$ of $\mathrm{D}_{\mathrm{PDM}}(\mathrm{e})$ Driving pulses to the switches $\mathrm{Q}_{1}$ and $\mathrm{Q}_{2}(\mathrm{f})$ Zoomed view of the Output voltage $(\mathrm{g})$ Zoomed view of the output current

(g)

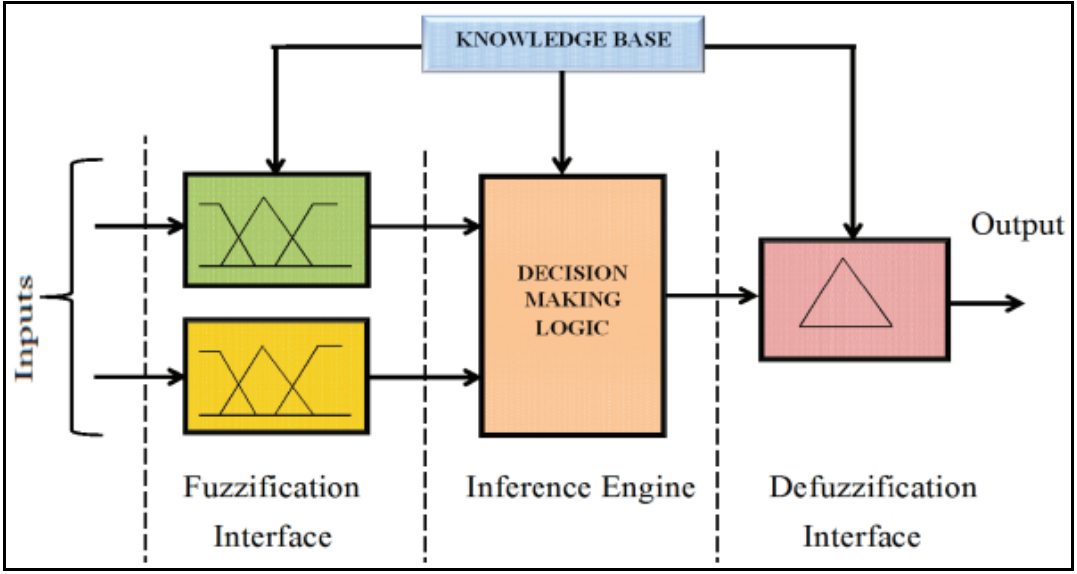

Fig. 8. Block diagram of FLC

Fuzzy logic is a nonlinear control technique, which is applied to the control of converters to improve the performance of the system as suggested in literature [1820]. Expert knowledge plays a vital role in designing the FLC and it could be used in the system which has large variations of input voltage or load. The performance of the controller is evaluated by the number of linguistic variables, the control range of linguistic variable and the slope of membership function. The fuzzy controller is robust to the variations in input DC voltage and load. FLC does not require the mathematical model of the system / process as like conventional controller but it is necessary to understand the system / process and the control requirements.

The information / data (control input variable) flows must be designed by the fuzzy controller designer, then the information / data is processed (control strategy and decision), and the corresponding control data flows out 


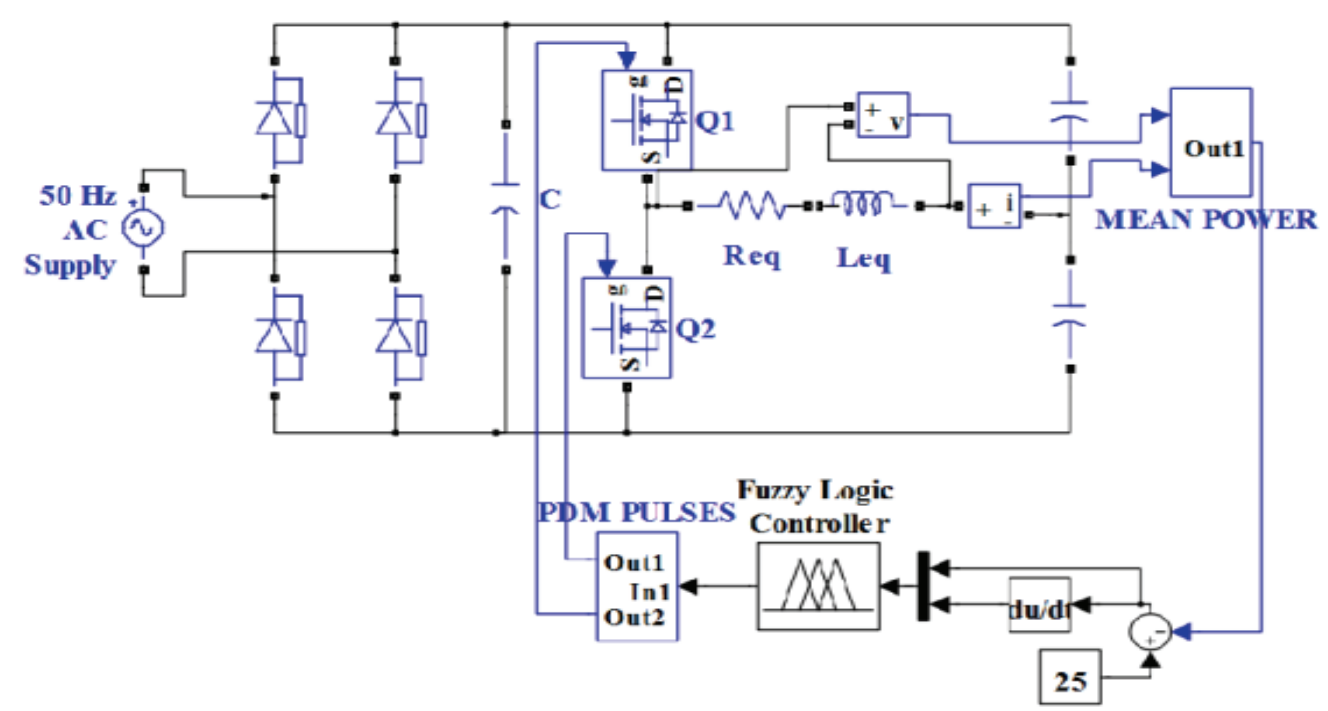

Fig. 9. Simulink model of the FLC based closed loop controlled IH power supply system.

of the system (solution/ output variable). The major development of fuzzy logic was primarily designed to represent and reason with some particular form of knowledge. The basic configuration of the fuzzy logic system is shown in Fig. 8.

The operation of the FLC involves three modules. They are fuzzification interface, knowledge based fuzzy reasoning mechanism and defuzzification modules to produce the control signal necessary for the plant. Fuzzy reasoning mechanism is used to convert the measured crisp values into fuzzy linguistic values. This process is called as fuzzification. In order to achieve the control goal, the collections of expert's control rules (knowledge) are needed. They are called as knowledge base. In this process, the fuzzy logic operations and the control actions are taken according to the fuzzy inputs. The process of converting the fuzzified values into the crisp value is called as defuzzification. The centre of area or centroid defuzzification is the most frequently used defuzzification technique which is also used in this work and is characterized by

$$
y=\frac{\sum \mu_{i} y_{i}}{\sum \mu_{i}}
$$

Where y represents the crisp value of the output of the fuzzy controller and $\mu$ is its membership grade. The MATLAB Simulink tool is used to test the performance of the FLC in the output power control of IH load. The output power needs to be varied according to the reference value set by the user. This is an important objective of the FLC based closed loop system considered in this work.

The simulink model of the closed loop control using FLC is shown in Fig. 9. The mean power is measured and compared with the set power to find the error (e). The inputs to the FLC are the error and the derivative of the

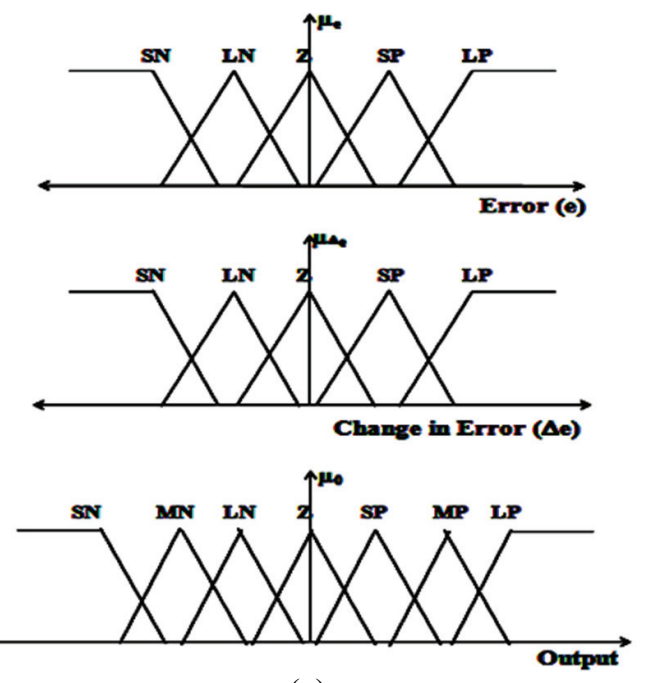

(a)

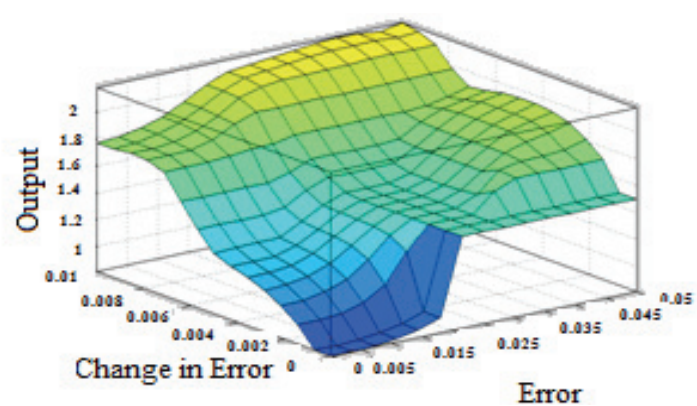

(b)

Fig. 10. (a) Membership function of the input and output variables of the FLC (b) Surface plot for error, change in error and control variable

error $(\Delta \mathrm{e})$ in power. The output of the controller is the control signal used to vary the $\mathrm{D}_{\mathrm{PDM}}$. The two inputs and one output of FLC are divided into five triangular membership functions as shown in Fig. 10(a). 


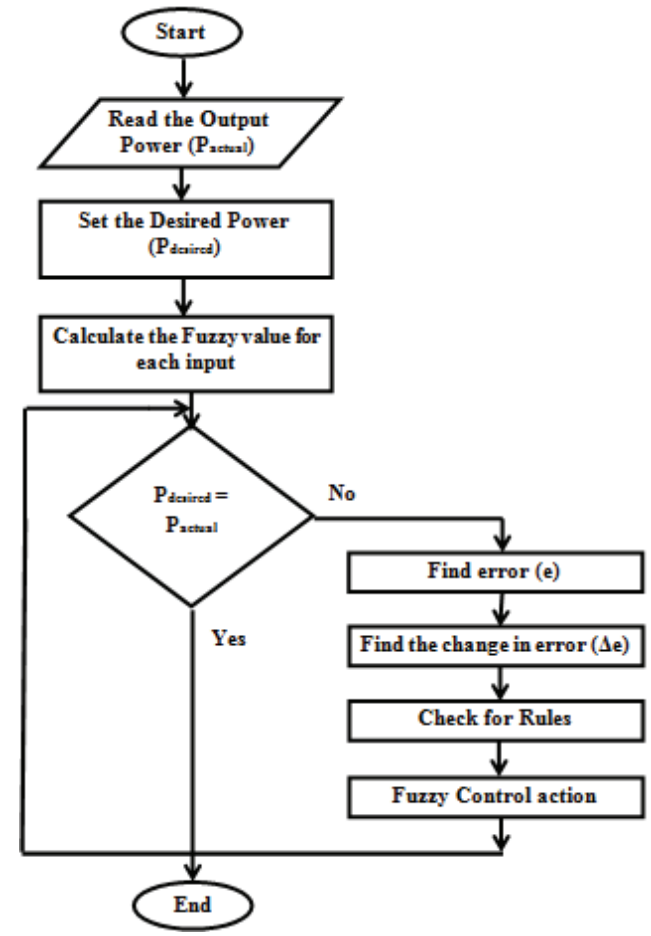

Fig. 11. Flow chart for the FLC based power control

With the basic control knowledge of diverging and converging system, the control action involved is based on the simple linguistic rules which are listed below.

1) If the error is large, change of $D_{P D M}$ must be large to bring the output equal to the reference power.

2) If the error is near zero, small change of $D_{\text {PDM }}$ is needed.

3 ) If the error is near zero and the derivative of error is large, the $\mathrm{D}_{\mathrm{PDM}}$ should be kept constant.

4) When the set point is reached and the output still changes, a very small change in $\mathrm{D}_{\mathrm{PDM}}$ is necessary to prevent the output moving away from the required value.

The surface plot which shows the variation of the controller output corresponding to the e and $\Delta \mathrm{e}$ is shown in Fig. 10 (b).

The rule base is developed for FLC scheme with the above points as reference and they are listed in Table 1. The flowchart of the FLC based power control is shown in Fig. 11. The control signal produced by the controller, based on the rule base is used to generate the PDM gate signals to the switches. The FLC is designed such that it tracks the reference power by changing the $\mathrm{D}_{\mathrm{PDM}}$ of the PDM signals.

The control signal at the output of the PID controller is $\mathrm{U}(\mathrm{s})$ and it can be defined as

$$
U(s)=\left(K_{p}+\frac{K_{i}}{S}+K_{d} S\right) e(s)
$$

Table 1. Fuzzy rule base

\begin{tabular}{c|c|c|c|c|c}
\hline $\mathrm{e} / \Delta \mathrm{e}$ & $\mathrm{SN}$ & $\mathrm{LN}$ & $\mathrm{Z}$ & $\mathrm{SP}$ & $\mathrm{LP}$ \\
\hline $\mathrm{SN}$ & $\mathrm{LP}$ & $\mathrm{MP}$ & MP & LN & SN \\
\hline $\mathrm{LN}$ & SP & MN & LN & MP & LN \\
\hline Z & SP & MP & Z & LN & SN \\
\hline SP & LP & LN & MN & LP & Z \\
\hline LP & MP & MN & SN & LN & LN \\
\hline
\end{tabular}

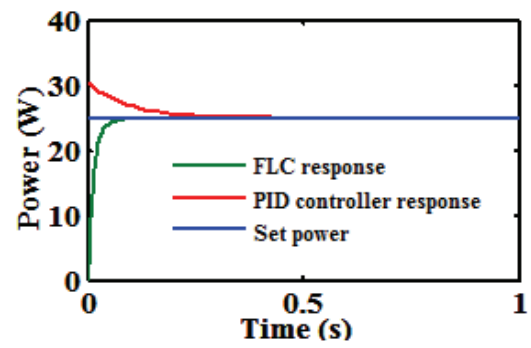

(a)

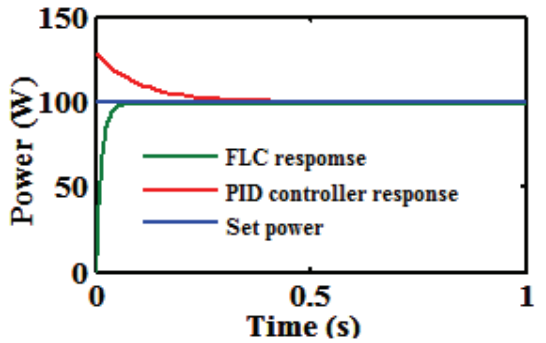

(b)

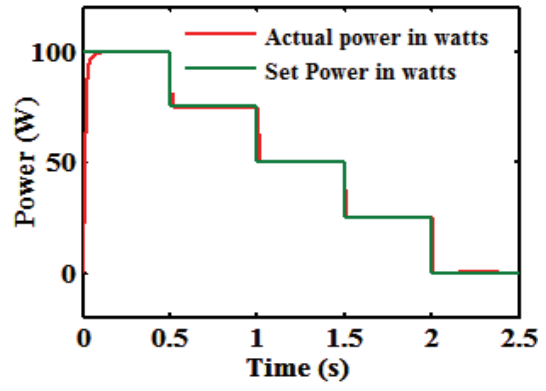

(c)

Fig.12. (a) Response with PID controller and FLC for set power of $25 \mathrm{~W}$ (b) Response with PID controller and FLC for set power of $100 \mathrm{~W}$ (c) Response of the system with FLC for variation of the power from $100 \mathrm{~W}$ to $0 \mathrm{~W}$

Where $K_{p}, K_{i}$ and $K_{d}$ are the proportional, integral and derivative gains of the PID controller for the given operating conditions. For the set power of $25 \mathrm{~W}$, the values of the $\mathrm{K}_{\mathrm{p}}, \mathrm{K}_{\mathrm{i}}$ and $\mathrm{K}_{\mathrm{d}}$ are equal to $0.9,1.6$ and 2.3 respectively. The gains of the PID controller are obtained using Ziegler and Nichols method. The control signal U(s) is used to produce the PDM based gate signals necessary to track the output power.

Figs. 12(a) and (b) illustrate the response of the system with the PID controller and FLC for the set power of $25 \mathrm{~W}$ and $100 \mathrm{~W}$ respectively. For the given values of the gains, 
the PID controller tracks the output power only for the set power of $25 \mathrm{~W}$. It has been found from the simulation study that the the PID controller requires different values of the gains when the set power is varied.

The variation of output power from $100 \mathrm{~W}$ to $0 \mathrm{~W}$ using the FLC is shown in Fig. 12 (c). The green line indicates the reference power. For every $0.5 \mathrm{~s}$, the reference power setting is made to decrease by $25 \mathrm{~W}$ from the rated power of $100 \mathrm{~W}$. The red line indicates the actual power of the inverter. It can be noted that the output power follows the reference power. Both the controllers track the reference power with zero steady state error. The effectiveness of the FLC can be studied using the settling time $\left(t_{s}\right)$. The comparison of the system using the conventional and the proposed controller for different values of set power are given in Table 2.

The PID controller and FLC system reach the steady

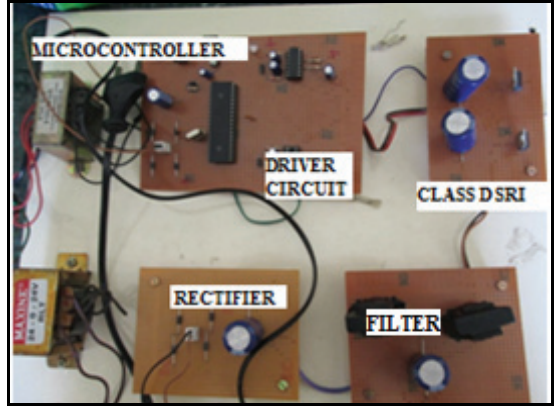

(a)

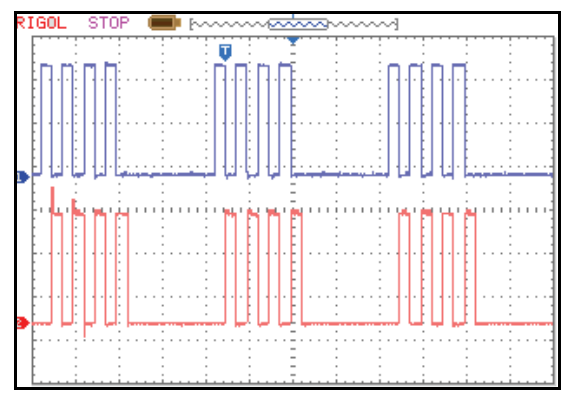

(c)

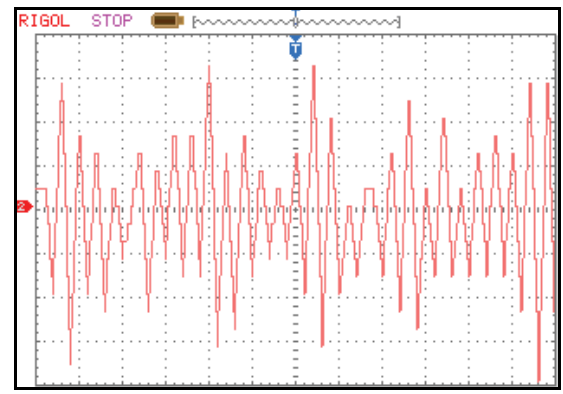

(e) state with the settling time of $0.44 \mathrm{~s}$ and $0.075 \mathrm{~s}$ respectively for the reference power of $25 \mathrm{~W}$. Thus a fast and smooth transition of power control is possible using the FLC without any oscillation. It is also observed that the proposed FLC tracks the output power for the entire power range whereas the PID controller requires tuning of the controller for every set value due to the nonlinear nature of the load.

Table 2. Comparison of the performance parameters with the PID and fuzzy logic controllers

\begin{tabular}{c|c|c|c|c}
\hline Parameters & \multicolumn{4}{|c}{ PID controller } \\
\hline $\mathrm{P}_{\mathrm{s}}(\mathrm{W})$ & 25 & 50 & 75 & 100 \\
\hline $\mathrm{t}_{\mathrm{s}}(\mathrm{s})$ & 0.44 & 0.47 & 0.59 & 0.76 \\
\hline Parameters & \multicolumn{3}{|c}{ FLC } \\
\hline $\mathrm{P}_{\mathrm{s}}(\mathrm{W})$ & 25 & 50 & 75 & 100 \\
\hline $\mathrm{t}_{\mathrm{s}}(\mathrm{s})$ & 0.075 & 0.06 & 0.052 & 0.049 \\
\hline
\end{tabular}

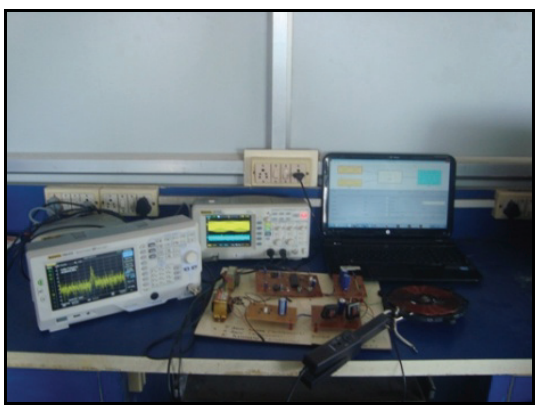

(b)

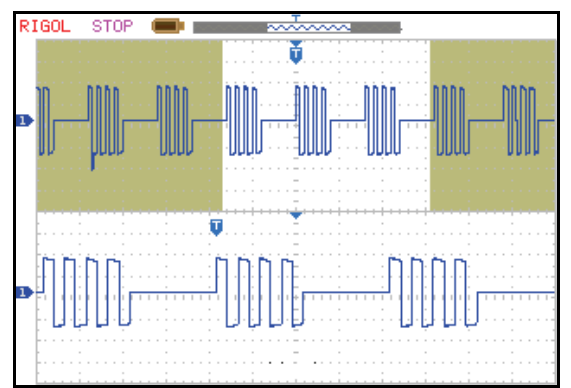

(d)

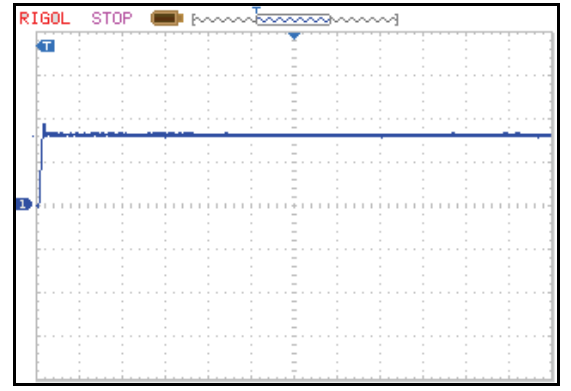

(f)

Fig.13. Hardware Results (a) Hardware layout of the IH power supply system (b) Test set up of the Hardware (c) Driving pulses to the switches $\mathrm{Q}_{1}$ and $\mathrm{Q}_{2}(\mathrm{X}$ axis $1 \mathrm{~cm}=2 \mathrm{~V}, \mathrm{Y}$ axis $1 \mathrm{~cm}=100 \mu \mathrm{s})(\mathrm{d})$ Output Voltage $(\mathrm{X}$ axis $1 \mathrm{~cm}=30 \mathrm{~V}$, $\mathrm{Y}$ axis $1 \mathrm{~cm}=100 \mu \mathrm{s}$ ) (e) Output current (X axis $1 \mathrm{~cm}=2 \mathrm{~A}$, Y axis $1 \mathrm{~cm}=200 \mu \mathrm{s}$ ) (f) Response of the system with FLC for set power of $25 \mathrm{~W}$ (X axis $1 \mathrm{~cm}=15 \mathrm{~W}$, Y axis $1 \mathrm{~cm}=100 \mu \mathrm{s})$. 


\section{Experimental Results}

A prototype of high frequency AC power supply circuit rated for $100 \mathrm{~W}$ was fabricated to validate the control scheme in class D inverter circuit. The simulation results of the IH power supply system using the proposed control technique are validated using the experimental results. The hardware layout of the system and the test setup of the system are shown in Figs.13(a) and 13(b) respectively. The full bridge uncontrolled rectifier was constructed using the four IN5408 diodes to supply DC to the class D inverter. The class D inverter was constructed using two IRF840 MOSFET switches for the conversion of DC into high frequency AC.

The control circuit for the PDM control strategy is implemented using a PIC16F877A micro controller. The micro controller produces the PDM pulses required by the switches $\mathrm{Q}_{1}$ and $\mathrm{Q}_{2}$. The pulses from the controller are amplified using IR2110 driver. It also provides the isolation between the power circuit and the control circuit. The output pulses from the driver circuit are shown in Fig. 13(c). The output voltage and current of SRI with $\mathrm{D}_{\mathrm{PDM}}$ of $25 \%$ are shown in Figs. 13(d) and 13(e) respectively. The current is measured using SIGLENT CP4060 type current probe. The waveforms are recorded using the RIGOL DS1052E type digital oscilloscope. The response of the system with FLC is shown in Fig. 13 (f). It can be observed that these oscillograms follow the theoretical and simulation results discussed in the previous sections. The obtained results confirm that the FLC track the set power with less settling time.

\section{Conclusion}

In this paper, the high-frequency IH power supply system is discussed with PDM technique and the power control is done using the FLC. The open and closed loop circuit models with PDM control are developed and they are successfully used for the simulation studies. The detailed study on PDM based SRI confirms the power control through the PDM duty cycle variation without the change in frequency. Experimental verification is also done through the PIC16F877A microcontroller. The PDM operation maintains soft switching condition for the entire load cycle. The closed loop control using PDM based FLC confirms that it tracks the reference power for the whole range of operation with different power settings. The proposed FLC system provides fast response. However, it requires the complete knowledge of the system to develop the rule base. The hardware response of the inverter system can be improved by replacing the PIC controller with DSP controller.

\section{References}

[1] J. Acero, J. M. Burd'10, L.A, Barrag'an, D. Navarro, R. Alonso, J. R. Garcia, F. Monterde, P. Hern'andez, S. Llorente, and I. Garde, "The domestic induction heating appliance: An overview of recent research," in Proc. Appl. Power Electron. Conf. Expo., 2008, pp. 651-657.

[2] O. Lucía, J. M. Burdío, I. Millán, J. Acero, and L. A. Barragán, "Efficiency oriented design of ZVS halfbridge series resonant inverter with variable frequency duty cycle control," IEEE Transactions on Power Electronics, vol. 25, no. 7, pp. 1671-1674, July 2010.

[3] H. Sarnago, A. Mediano, and O. Lucía, "High efficiency ac-ac power electronic converter applied to domestic induction heating," IEEE Transactions on Power Electronics, vol. 27, no. 8, pp. 3676- 3684, August 2012.

[4] B. Saha, K. Soon Kurl, N. A. Ahmed, H. Omori, and M. Nakaoka, "Commercial frequency AC to high frequency $\mathrm{AC}$ converter with boost-active clamp bridge single stage ZVS-PWM inverter," IEEE Transactions on Power Electronics, vol. 23, no. 1, pp. 412-419, January 2008.

[5] N. J. Park, D. Y. Lee, and D. S. Hyun, "A powercontrol scheme with constant switching frequency in class-D inverter for induction-heating jar application," IEEE Transactions on Industrial Electroics, Vol. 54, No. 3, pp. 1252- 260, June 2007.

[6] O. Lucía, J. M. Burdío, L. A. Barragán, J. Acero, and C. Carretero, "Series resonant multi-inverter with discontinuous-mode control for improved light-load operation," IEEE Transactions on Industrial Electronics, vol. 58, no. 11, pp. 5163-5171, November 2011.

[7] V. Esteve, E. Sanchis-Kilders, J. Jordán, E. J. Dede, C. Cases, E. Maset, J. B. Ejea, and A. Ferreres, "Improving the efficiency of IGBT series resonant inverters using pulse density modulation," IEEE Transactions on Industrial Electronics, vol. 58, no. 3, pp. 979-987, March 2011.

[8] O. Lucia, J. M. Burdio, I. Millan, J. Acero, and L. A. Barragan, "Efficiency-oriented design of ZVS half-bridge series resonant inverter with variable frequency duty cycle control," IEEE Transactions on Power Electronics, vol. 25, no. 7, pp. 1671-1674, Jul. 2010.

[9] N. A. Ahmed and M. Nakaoka, "Boost-half-bridge edge resonant soft switching PWM high-frequency inverter for consumer induction heating appliances," IEE Proc. Electr. Power Appl., vol. 153, no. 6, pp. 932-938, Nov. 2006.

[10] H. Pham, H. Fujita, K. Ozaki, and N. Uchida, "Phase angle control of high-frequency resonant currents in a multiple inverter system for zone-control induction heating," IEEE Transactions on Power Electronics, vol. 26, no. 11, pp. 3357-3366, 2011. 
[11] C. Carretero, O. Lucia, J. Acero, and J. M. Burdio, "Phase-shift control of dual half-bridge inverter feeding coupled loads for induction heating purposes," Electronics Letters, vol. 47, no. 11, pp. 670671, May 2011.

[12] O. Luc'1a, J. M. Burd'10, I. Mill'an, J. Acero, and D. Puyal, "Load-adaptive control algorithm of halfbridge series resonant inverter for domestic induction heating," IEEE Transactions on Industrial Electronics, vol. 56, no. 8, pp. 3106- 3116, August 2009.

[13] J. K. Byun, K. Choi, H. S. Roh, and S. Y. Hahn, "Optimal design procedure for a practical induction heating cooker," IEEE Trans. Magn., Vol. 36, No. 4, pp. 1390-1393, Jul. 2000.

[14] O. Luc'1a, C. Carretero, D. Palacios, D. Valeau, and J. M. Burd'10, "Configurable snubber network for efficiency optimization of resonant converters applied to multi-load induction heating," Electronics Letters., vol. 47, no. 17, pp. 989-991, Aug. 2011.

[15] O. Luc'1a, L. A. Barrag'an, J. M. Burd'10, O. Jim'enez, D. Navarro, and I. Urriza, "A versatile power electronics test-bench architecture applied to domestic induction heating," IEEE Transactions on Industrial Electronics, vol. 58, no. 3, pp. 998-1007, March 2011.

[16] D. J. Tschirhart and P. K. Jain, "A CLL resonant asymmetrical pulse width modulated converter with improved efficiency", in IEEE Transactions on Industrial Electronics,Vol. 55, no 1, pp. 114-122, 2008.

[17] P. Viriya, N. Yongyuth, and K. Matsuse, "Analysis of two continuous control regions of conventional phase shift and transition phase shift for induction heating inverter under ZVS and non-ZVS", in IEEE Transaction on Power Electronics, Vol. 23, no 6, pp. 2794-2804, 2008.

[18] Balestrino, A. Landi, and L. Sani, "CUK converter global control via fuzzy logic and scaling factor," IEEE Transactions on Industrial Electronics, vol. 38, no. 2, pp. 406-413, Mar./Apr. 2002.

[19] E. Vidal, L. Martine, F. Guinjoan, J. Calvente, and S. Gomariz, "Sliding and fuzzy control of a boost converter using an 8-bit microcontroller," in Proc. Inst. Elect. Eng., Electr. Power Appl., vol. 151, no. 1, pp. 5-11, Jan. 2004.

[20] T.Gupta and R. R. Boudreaux, "Implementation of a fuzzy controller for DC-DC converters using an inexpensive 8-bit micro-controller," IEEE Transactions on Industrial Electronics, vol. 44, no. 5, pp. 661-669, October 1997.

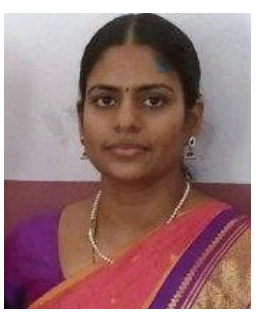

Booma Nagarajan She is a research scholar in the Department of Electrical and Electronics Engineering, Jerusalem College of Engineering, Centre for Collaborative Research, Chennai, India She obtained her D.E.E.E from Thiagarajar Polytechnic, Salem; T.N in 1997. She received her B.E degree in Electrical Electronics Engineering from Madras University, Chennai, India in 2000, M.E. degree in Power Systems Engineering from College of Engineering, Guindy, Anna University, Chennai, India in 2007. She has 13 years of teaching experience. She has published over 22 Technical papers in National and International Conferences Proceedings / Journals. Her research interests include resonant inverters for induction heating intelligent controllers and power quality.

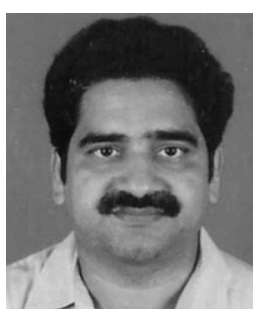

Rama Reddy Sathi He is professor in the Department of Electrical \& Electronics Engineering Department, Jerusalem College of Engineering, Chennai, India. He obtained his D.E.E.E from S.M.V.M. polytechnic, Tanuku, A.P., A.M.I.E. in Electrical Engineering from Institution of Engineers (India), M.E. in Power Systems from Anna University, Chennai and Ph.D in the area of Power Electronics from Anna University, Chennai, India. He has published over 80 Technical papers in National and International Conferences proceedings / journals. He has secured A.M.I.E. Institution gold medal for obtaining the highest marks. He has secured AIMO best project award and ISTE National level Best teacher Award. He has 20 years of teaching experience. His research interests include the areas of resonant converters and FACTS. He has received funds for MODROBS and Research and development from All India Council of Technical Education (AICTE) He is a life member of the Institution of Engineers (India), Indian Society for Technical Education, Systems Society of India, Society of Power Engineers and Institution of Electronics and Telecommunication Engineers (India).

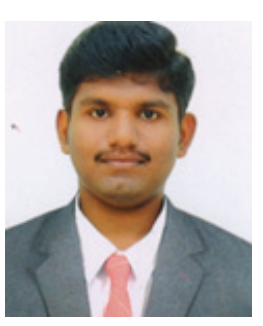

Pradeep Vishnuram He is Assistant professor in Jerusalem college of Engineering, Chennai, India. He received his B.E degree in Electrical and Electronics Engineering from J. J College of Engineering and Technology, Trichy, Tamil Nadu in 2012. His interests include the resonant converters for induction heating, intelligent controllers and high power factor rectifiers. 